\title{
TÁC ĐộNG CÁC YẾU TỐ KINH TẾ VĨ MÔ TỚI TY̛ GIÁ TRỰC TIẾP GIỮA USD VÀ VND - BẰNG CHỨNG THỰC NGHIỆM TẠI VIỆT NAM
}

ThS. Truóng Thị Hoà ${ }^{1}$

TS. Ngô Đức Tiến ${ }^{2}$

\section{Tóm tắt}

Bài nghiên cứu tập trung vào việc xác định và đo lường ảnh hưởng của các yếu tố kinh tế vĩ mô gồm thu nhập, lãi suất, kiều hối và dụ trũ ngoại hối tới tỷ giá tại Việt Nam. Bài nghiên cưu được thục hiện với ba buớc chính: Uớc luợng mô hình VAR, kiểm định nhân quả Granger, và phân tích hàm phản ứng xung. Kết quả nghiên cứu cho thấy các yếu tố kinh tế vĩ mô thuộc về chính sách tiền tệ gồm: lãi suất, dụ trũ ngoại hối có tác động tới tỷ giá USD tại Việt Nam.

Tù khoá: Tỷ giá, lãi suất, dự trữ ngoại hối, thu nhập, kiều hối

\section{Giới thiệu}

Tỷ giá hối đoái là giá trị đồng tiền nước này được tính theo đồng tiền nước khác và là giá trị thường xuyên biến động, khó dự báo. Nó tác động đến nền kinh tế và cuộc sống hàng ngày của người dân vì khi giá trị đồng nội tệ tăng lên sẽ khiến giá hàng trong nước đắt một cách tương đối so với hàng nước ngoài. (Mankiw 2012, Mishkin, Matthews, Giuliodori 2013). Do đó, tỷ giá là một công cụ tốt nhằm tạo lập các điều kiện thuận lợi, đồng thời duy trì mức độ cạnh tranh của nền kinh tế (Phạm Minh Chính, Vương Quân Hoàng 2009). Với các lý do như trên, chính sách tỷ giá có thể được coi là một trong những chính sách tiền tệ quan trọng nhất của một nền kinh tế mở. Mặt khác, hiện nay, USD vẫn được coi là đồng tiền mạnh nhất thế giới với gần $80 \%$ các giao dịch trên thị trường ngoại hối có sử dụng đồng USD (Bloomberg). Ở Việt Nam, USD đóng vai trò tương tự khi chiếm tới $60 \%$ dự trữ ngoại hối của ngân hàng nhà nước (NHNN) (Lê Thị Tuấn Nghĩa, Phạm Thị Hoàng Anh 2013), đồng thời là đồng tiền chủ yếu được sử dụng trong hoạt động xuất nhập khẩu ở Việt Nam. Do đó, việc điều hành và kiểm soát tỷ giá USD đã và đang là một trong những trọng tâm của NHNN nhằm hướng tới mục tiêu tăng trưởng lâu dài và ổn định.

Từ năm 1991, NHNN liên tục áp dụng chính sách neo tỷ giá với biên độ được

\footnotetext{
${ }^{1}$ Trường Đại học Sư phạm Kỹ thuật TP.HCM. Email: hoatrt@hcmute.edu.vn

${ }^{2}$ Học viện Tài chính. Email: vcb.dtda.1 @ gmail.com

180
} 
điều chỉnh (Uỷ ban kinh tế của Quốc hội, "Báo cáo kinh tế vĩ mô 2014"), tỷ giá USD được hình thành trên cơ sở cung cầu ngoại tệ trên thị trường có sự điều tiết của nhà nước. Tuy nhiên, trong giai đoạn từ năm 1992 tới nay, tỷ giá USD của Việt Nam cũng có sự biến động liên tục từ 11.202 VND lên tới 20.148 VND vào năm 2014. Vấn đề đặt ra ở đây là việc USD liên tục tăng giá (VND liên tục giảm giá) trong thời gian dài như trên có phải là chính sách của NHNN hay xuất phát từ ảnh hưởng của các yếu tố trong cung, cầu USD trên thị trường Việt Nam. Do đó, việc xác định và đánh giá tác động các yếu tố kinh tế vĩ mô đến tỷ giá USD tại Việt Nam là hoàn toàn cần thiết để dự báo xu hướng tỷ giá USD trong thời gian tới và đề xuất các chính sách cũng như biện pháp phù hợp để đối phó với tình trạng trên.

\section{Lược khảo một số nghiên cứu liên quan đến chủ đề nghiên cứu}

Theo Mishkin (2013), tỷ giá hối đoái là giá cả đồng tiền nước này theo một đồng tiền nước khác. Trong chế độ tỷ giá thả nổi, tỷ giá ngoại tệ được xác định bởi cung cầu trên thị trường ngoại hối, nơi các đồng tiền khác nhau được mua bán. Khi phân tích tỷ giá, các nhà kinh tế học thường sử dụng việc phân tích mô hình cung cầu và cho rằng biến động tỷ giá xảy ra do biến động cung, cầu ngoại tệ trên thị trường. Jan Frait và Lubos Komarek (2003) đã sử dụng mô hình cân bằng tỷ giá và chia các yếu tố tác động thành hai nhóm lớn: nhóm các yếu tố tác động đến cung và cầu. Mishkin (2013) và Andrew B. Abel, Ben S.Bernanke, and Dean Croushore (2007) cũng phân tích tỷ giá bằng việc sử dụng mô hình cung cầu ngoại tệ. Frenkel và Mussa cho rằng điều kiện để đạt được cân bằng trên thị trường giao dịch quốc tế gồm xuất, nhập khẩu và dòng vốn thường được coi là yếu tố xác định tỷ giá. Tương tự, khi phân tích mô hình cung cầu ngoại tệ, Andrew B. Abel, Ben S.Bernanke, and Dean Croushore (2007) khẳng định cầu ngoại tệ trên thị trường được hình thành do hai lý do chính: Để có thể mua hàng hoá dịch vụ từ nước ngoài và để có thể mua tài sản tài chính từ nước ngoài. Cung ngoại tệ trên thị trường được hình thành do hai lý do chính: Từ việc bán hàng hoá dịch vụ ra nước ngoài và từ việc người nước ngoài mua tài sản tài chính trong nước. Những yếu tố gia tăng cầu nhập khẩu và mua tài sản tài chính từ nước ngoài sẽ gia tăng cầu ngoại tệ, thông qua đó khiến tỷ giá ngoại tệ tăng lên. Tương tự các yếu tố gia tăng cầu xuất khẩu và cầu mua tài sản tài chính trong nước của người nước ngoài sẽ gia tăng cung về ngoại tệ trên thị trường. Các yếu tố trên chính là hai thành phần chính trong cán cân thanh toán là tài khoản vãng lai và tài khoản vốn³. Các yếu tố tác động tới

\footnotetext{
${ }^{3}$ Điều này được Dornbusch (1975), Kouri (1978), Mishkin (2013), Adrew B. Abel, Ben S.Bernanke, and Dean Croushore 2007 công nhận và đưa vào các nghiên cứu của mình
} 
cung cầu bao gồm: thu nhập và lãi suất thực trong nước, ngoài nước. ${ }^{4}$

Mặt khác, theo Đỗ Thị Kim Hảo (2013) hay Đỗ Đức Thành (2008) bên cạnh các yếu tố trên thì kiều hối đóng một vai trò rất lớn trong thị trường ngoại tệ Việt Nam. Lượng kiều hối chảy về Việt Nam chiếm tỷ trọng lớn, chỉ chiếm thứ hai sau dòng vốn FDI so với các dòng tài chính khác, do đó nó tạo thành một nguồn cung ngoại tệ rất lớn và tác động trực tiếp đến tỷ giá USD trên thị trường.

Ngoài việc tỷ giá chịu tác động bởi cơ chế cung cầu được mô tả ở trên, các nhà kinh tế học như Mills, Wood (1978), Andrew B. Abel, Ben S.Bernanke, and Dean Croushore (2007) cũng cho rằng ngân hàng trung ương (NHTW) các quốc gia hoàn toàn có thể can thiệp vào thị trường ngoại tệ và điều chỉnh tỷ giá phù hợp với mục tiêu chính sách đưa ra. NHTW các quốc gia thường can thiệp vào thị trường ngoại tệ bằng cách tham gia trực tiếp với vai trò người bán, người mua để điều chỉnh tỷ giá. Trong trường hợp tỷ giá trên thị trường cao hơn kỳ vọng của NHTW, NHTW sẽ tham gia vào thị trường như một người cung ngoại tệ bằng cách bán một phần ngoại tệ trong dự trữ ngoại hối. Hành động này của NHTW sẽ khiến cung ngoại tệ tăng lên khiến tỷ giá giảm xuống về mức tỷ giá chính thức. Tuy nhiên, việc bán một phần dự trữ ngoại hối sẽ khiến dự trữ ngoại hối của quốc gia giảm xuống. Ngược lại, NHTW sẽ can thiệp bằng cách mua vào ngoại tệ trên thị trường nhằm tăng cầu ngoại tệ. Hành động này sẽ khiến tỷ giá thị trường tăng về bằng với tỷ giá chính thức đồng thời khiến dự trữ ngoại hối tăng lên. Như vậy, chúng ta có thể thấy việc thay đổi dự trữ ngoại hối của NHTW có tác động trực tiếp đến thị trường ngoại tệ và khiến tỷ giá trên thị trường biến động. Khi NHTW tăng dự trữ bằng cách mua vào sẽ có xu hướng tác động khiến tỷ giá tăng; ngược lại, khi NHTW giảm dự trữ bằng cách bán ra sẽ khiến tỷ giá giảm.

\section{Mô hình nghiên cứu}

Hiện nay, Việt Nam theo đuổi chính sách tỷ giá thả nổi có sự điều tiết của NHNN. Do đó, ta có mô hình nghiên cứu tỷ giá USD theo các yếu tố kinh tế vĩ mô như sau:

$\mathrm{ER}=\mathrm{f}\left(\mathrm{Y}, \mathrm{r}, \mathrm{r}_{\mathrm{us}}\right.$, Rem, Res $)$

Trong đó:

ER: Tỷ giá USD tại Việt Nam

Y: Thu nhập bình quân đầu người Việt Nam

r: Lãi suất thực tại Việt Nam

rus: Lãi suất thực tại Hoa Kỳ

Rem: Kiều hối

\footnotetext{
${ }^{4}$ Điều này cũng đã được Frait, Komarek (2003); Egert (2003) khẳng định
} 
Res: Dự trữ ngoại hối Việt Nam

\section{Thiết kế nghiên cứu}

\section{Thu thập dữ liệu}

Số liệu kinh tế vĩ mô được thu thập theo quý trong giai đoạn từ quý 1 năm 2000 tới quý 4 năm 2014 (60 quan sát). Số liệu này cũng được thu thập từ nhiều nguồn khác nhau. Tỷ giá USD được biểu diễn dưới dạng USD theo VND (Ví dụ: ER = 21.000 nghĩa là $1 \mathrm{USD}=21.000 \mathrm{VND}$ ) và được thu thập từ thống kê tài chính quốc tế (International Financial Statistics_IFS) của Quỹ Tiền tệ Quốc tế (IMF). Thu nhập bình quân đầu người Việt Nam được tính theo đơn vị VND từ số liệu của Tổng cục Thống kê và Ngân hàng Thế giới (WB). Số liệu lãi suất thực và dự trữ ngoại hối được thu thập từ IMF.

\section{Mô hình kinh tế lượng và phương pháp xử lý số liệu}

Mô hình (1) ở trên là mô hình chuỗi thời gian với các biến có sự tác động qua lại với nhau ${ }^{5}$, các biến này chịu tác động không chỉ bởi giá trị hiện tại mà còn cả giá trị trong quá khứ với độ trễ thời gian nhất định ${ }^{6}$. Do các lý do như trên, mô hình VAR được lựa chọn để ước lượng và kiểm định mô hình nghiên cứu. Mô hình VAR đơn giản có dạng như sau:

$$
Y_{t}=C+\theta_{1} Y_{t-1}+\theta_{2} Y_{t-2}+\ldots .+\theta_{p} Y_{t-p}+\varepsilon_{t}
$$

Trong đó:

- p là độ trễ các biến trong mô hình

- $\mathrm{Y}_{\mathrm{t}} \ldots \mathrm{Y}_{\mathrm{t}-\mathrm{p}}$ là véc tơ các biến trong phương trình $\mathrm{Y}=\left(\mathrm{ER}, \mathrm{Y}, \mathrm{r}, \mathrm{r}_{\mathrm{us}}, \mathrm{Rem}, \mathrm{Res}\right)$. Trước khi đưa vào để ước lượng và kiểm định theo mô hình VAR, các biến của mô hình ngoại trừ lãi suất $r$ và $\mathrm{r}_{\text {us }}$ sẽ được lấy logarit tự nhiên để giảm bớt độ lệch. Riêng biến thu nhập $(Y)$ chịu nhiều ảnh hưởng của yếu tố mùa vụ nên sẽ được xử lý tính mùa vụ trước khi đưa vào mô hình.

- C là véc tơ các hằng số

- $\varepsilon_{t}$ là véc tơ các sai số.

Nghiên cứu sử dụng phần mềm Eviews 6 để xử lý số liệu qua bốn bước sau:

Bước 1: Kiểm định tính dừng của các biến quan sát. Bước 2: Ước lượng mô hình

\footnotetext{
${ }^{5}$ Ví dụ: Thu nhập thực tế $(\mathrm{Y})$ có tác động đến tỷ giá $\mathrm{EX}$, tuy nhiên theo chiều ngược lại thì EX cũng có tác động đến $\mathrm{Y}$ vì $\mathrm{Y}=\mathrm{C}+\mathrm{I}+\mathrm{G}+\mathrm{NX}$. EX thay đổi sẽ có sự tác động đến $\mathrm{NX}$ thông qua đó tác động tới $\mathrm{Y}$

${ }^{6}$ Ví dụ: ER có thể không chỉ chịu tác động bởi lãi suất thực của Việt Nam hiện nay mà lãi suất thực của Việt Nam cũng có thể góp phần ảnh hưởng đến tỷ giá hối đoái trong kỳ hiện hành
} 
VAR. Bước 3: Kiểm định nhân quả Granger. Bước 4: Phân tích hàm phản ứng xung (Impulse Response Function - IRF).

\section{Kết quả nghiên cứu}

Kết quả nghiên cứu sẽ được trình bày theo bốn bước đã được nêu ở trên.

\section{Kiểm định tính dừng và xử lý tính dừng}

\section{Kiểm định tính dùng}

Mô hình VAR yêu cầu tất cả các biến nghiên cứu đều phải có tính dừng do đó trước khi đi vào ước lượng mô hình $\mathrm{VAR}$, nghiên cứu sẽ thực hiện kiểm định tính dừng đối với tất cả các biến. Phương pháp kiểm định nghiệm đơn vị ADF (Augmented Dickey-Fuller) được sử dụng để kiểm tra tính dừng.

Việc kiểm định tính dừng các biến cho kết quả như sau:

Bảng 1. Kết quả kiểm định tính dừng

\begin{tabular}{|l|r|r|}
\hline & Thống kê t & \multicolumn{1}{|c|}{ Xác suất } \\
\hline LER & -1.55352 & 0.7992 \\
\hline LY $_{\mathrm{sa}}$ & -5.20595 & 0.0004 \\
\hline $\mathrm{r}$ & -3.00747 & 0.1391 \\
\hline $\mathrm{r}_{\mathrm{us}}$ & -3.758693 & 0.0261 \\
\hline LRem & -3.76968 & 0.0253 \\
\hline LRes & -1.34493 & 0.8666 \\
\hline
\end{tabular}

Nguồn: Xứ lý dũ liệu tù Eviews 6

Kết quả xử lý dữ liệu cho thấy: Trong các biến nêu trên, dữ liệu của biến thu nhập bình quân đầu người Việt Nam, lãi suất thực Hoa Kỳ và kiều hối có giá trị tuyệt đối của thống kê $\mathrm{t}$ lớn hơn giá trị tới hạn tại mức ý nghĩa $1 \%$ hoặc $5 \%$. Điều này có nghĩa rằng, với mức ý nghĩa $1 \%$ hoặc $5 \%$ chúng ta có thể bác bỏ giả thuyết $\mathrm{H}_{0}$ : $\mathrm{LY}_{\mathrm{sa}}$, $\mathrm{r}_{\text {us }}$, LRem có nghiệm đơn vị; nói cách khác dữ liệu ba biến trên có tính dừng. Các biến còn lại bao gồm LER, r, LRes đều không có tính dừng (giá trị tuyệt đối của t-statistic nhỏ hơn giá trị tới hạn nên chúng ta không có căn cứ để bác bỏ giả thuyết $\mathrm{H}_{0}$ ).

\section{Xủ lý tính dùng}

Để xử lý trường hợp các dữ liệu không dừng, các biến còn lại được lấy sai phân bậc một. Sau khi tiếp tục kiểm định tính dừng với phương pháp nghiệm đơn vị $\mathrm{ADF}$, kết quả cho thấy các biến DLER, DR, DLRes đều có tính dừng với mức ý nghĩa $1 \%$. Kết quả kiểm định tính dừng sau khi lấy sai phân bậc một và bậc hai như sau.

\section{Bảng 2. Kết quả kiểm định tính dừng sau khi lấy sai phân bậc 1}




\begin{tabular}{|l|r|r|}
\hline & \multicolumn{1}{|c|}{ Thống kê t } & \multicolumn{1}{|c|}{ Xác suất } \\
\hline DLER & -7.62972 & 0 \\
\hline DR & -5.091 & 0.0006 \\
\hline DLRes & -6.20055 & 0 \\
\hline
\end{tabular}

Nguồn: Xử lý dĩ liệu tù Eviews 6

Như vậy, sau khi kiểm định tính dừng và xử lý các biến, chúng ta có véc tơ các biến trong mô hình Var (2) như sau:

$$
\mathrm{Y}=\left(\mathrm{DLER}, \mathrm{LY}_{\mathrm{sa}}, \mathrm{Dr}, \mathrm{r}_{\mathrm{us}}, \mathrm{LRem}, \mathrm{DLRes}\right)
$$

\section{Ước lượng mô hình VAR}

Các biến sau khi được xử lý tính dừng sẽ được đưa vào ước lượng theo mô hình VAR. Độ trễ phù hợp của mô hình VAR được chọn là $p=5$ theo hai tiêu chí $L R$ và AIC. Kết quả sau khi ước lượng mô hình VAR sẽ được đưa vào để kiểm định nhân quả Granger.

\section{Kiểm định nhân quả Granger}

Để xác định và kiểm định các yếu tố kinh tế vĩ mô nào có tác động tới tỷ giá, phương pháp kiểm định nhân quả Granger được sử dụng. Kiểm định nhân quả Granger cho kết quả như sau:

Bảng 3. Kết quả kiểm định nhân quả Granger

\begin{tabular}{|l|r|r|r|}
\hline \multicolumn{5}{|c|}{ Biến phụ thuộc: DLER } \\
\hline \multicolumn{1}{|c|}{ Excluded } & Chi-sq & \multicolumn{1}{c|}{ df } & \multicolumn{1}{c|}{ p-value } \\
\hline LY $_{\mathrm{sa}}$ & 6.135774 & 5 & 0.2932 \\
\hline $\mathrm{Dr}$ & 25.99773 & 5 & 0.0001 \\
\hline $\mathrm{r}_{\mathrm{us}}$ & 6.854085 & 5 & 0.2317 \\
\hline LRem & 12.72867 & 5 & 0.0261 \\
\hline DLRes & 18.9089 & 5 & 0.002 \\
\hline All & 88.66204 & 25 & 0 \\
\hline
\end{tabular}

Nguồn: Xử lý dĩu liệu tù̀ Eviews 6

Kết quả của kiểm định nhân quả Granger cho thấy: Với mức ý nghĩa 5\% thì các biến lãi suất thực Việt Nam, kiều hối, và dự trữ ngoại hối đều có giá trị p-value < $5 \%$. Với giá trị $\mathrm{p}$-value như trên, chúng ta bác bỏ giả thuyết $\mathrm{H}_{0}$ đồng nghĩa với việc chấp nhận giả thuyết $\mathrm{H}_{1}$ rằng tỷ giá USD tại Việt Nam chịu tác động bởi các yếu tố kinh tế vĩ mô đó là lãi suất thực tại Việt Nam, kiều hối và dự trữ ngoại hối của Việt Nam. Hai yếu tố còn lại là thu nhập Việt Nam, lãi suất tại Hoa Kỳ thì chúng ta chưa có căn cứ để bác bỏ giả thuyết $\mathrm{H}_{0}$ do đó chưa có căn cứ để khẳng định rằng có yếu tố đó thì có tác 
động đến tỷ giá USD. Xét trong chiều ngược lại thì yếu tố tỷ giá không tác động đến các biến kinh tế vĩ mô còn lại.

Để kiểm định tính không thiên lệch của mô hình, bài nghiên cứu sử dụng phương pháp Breusch-Godfrey để kiểm định hiện tượng tương quan chuỗi với dữ liệu các biến. Kết quả kiểm định cho thấy mô hình chúng ta nghiên cứu là một mô hình khá tốt khi không tồn tại hiện tượng tương quan chuỗi giữa các biến.

\section{Phân tích hàm phản ứng xung}

Việc kiểm định nhân quả Granger không thể làm rõ toàn bộ tác động của các biến tới tỷ giá USD, do nó mới chỉ cho thấy yếu tố kinh tế vĩ mô nào sẽ có tác động tới tỷ giá với độ trễ $\mathrm{p}=5$ mà chưa đánh giá được mức độ tác động này. Để làm rõ mức độ tác động, nghiên cứu tiếp tục phân tích hàm phản ứng xung của các biến lãi suất Việt Nam, dự trữ ngoại hối, kiều hối tới tỷ giá trong mười kỳ tiếp theo. Việc phân tích IRF sẽ cho thấy phản ứng của một biến khi có tăng lên một đơn vị phân phối chuẩn của một biến khác ${ }^{7}$.

Kết quả nghiên cứu cho thấy phản ứng của tỷ giá khi có sự thay đổi một đơn vị phân phối chuẩn của các biến tương ứng. Kết quả phân tích thể hiện ở Hình 1 cho thấy, các yếu tố lãi suất Việt Nam và dự trữ ngoại hối có tác động khá rõ rệt và có ý nghĩa thống kê lên tỷ giá trong các kỳ đầu tiên. Trong đó, tỷ giá chịu tác động nghịch chiều, có ý nghĩa thống kê bởi sự thay đổi của lãi suất trong ba kỳ đầu tiên, và tác động mạnh mẽ nhất tại kỳ thứ ba. Kết quả trên là hoàn toàn phù hợp với những gì mà lý thuyết kinh tế vĩ mô dự báo mà theo đó khi lãi suất tại Việt Nam tăng lên sẽ góp phần khiến cung ngoại tệ tăng, cầu ngoại tệ giảm và khiến tỷ giá USD giảm. Tuy nhiên, tác động này không ổn định và không có ý nghĩa thống kê trong các kỳ tiếp theo. Yếu tố tỷ giá cũng chịu tác động nghịch chiều và có ý nghĩa thống kê bởi dự trữ ngoại hối trong ba kỳ đầu tiên và chịu ảnh hưởng mạnh mẽ nhất tại kỳ thứ ba. Tuy nhiên, tác động này trái ngược với những gì mà lý thuyết kinh tế vĩ mô đã dự báo. Theo lý thuyết kinh tế vĩ mô thì việc NHNN tăng dự trữ ngoại hối sẽ làm tăng cầu USD dẫn đến tỷ giá USD tại Việt Nam sẽ có xu hướng tăng lên. Kết quả nghiên cứu ngược chiều này có thể được lý giải bởi việc, ngoài các yếu tố kinh tế vĩ mô được tính tới trong mô hình nghiên cứu, dự trữ ngoại hối và tỷ giá USD tại Việt Nam chịu tác động rất lớn bởi các cú sốc từ bên ngoài. Lê Thị Tuấn Nghĩa và Phạm Thị Hoàng Anh (2013) cho rằng dự trữ ngoại hối và tỷ giá USD Việt Nam giai đoạn 2006 - 2008 chịu tác động rất lớn bởi việc gia

\footnotetext{
${ }^{7}$ Den Haan, Wouter J., Garey Ramey, and Joel Watson. 2000. "Job Destruction and Propagation of Shocks." American Economic Review, 90(3): 482-498
} 
nhập WTO, đến giai đoạn từ năm 2009 lại chịu ảnh hưởng rất mạnh mẽ bởi khủng hoảng tài chính thế giới.

Ngoài ra, kết quả phân tích IRF cũng cho thấy, tác động của kiều hối tới tỷ giá USD là tác động nghịch chiều trong các kỳ đầu tiên, điều này hoàn toàn phù hợp với những gì mà lý thuyết dự báo. Nguồn kiều hối gia tăng sẽ khiến cung ngoại tệ tăng và khiến tỷ giá USD giảm. Tuy nhiên, tác động nghịch chiều của kiều hối ở đây còn chưa thực sự rõ rệt và không có ý nghĩa thống kê như hai yếu tố lãi suất và dự trữ ngoại hối.

Hình 1. Phân tích IRF của lãi suất, dự trữ ngoại hối, kiều hối tới tỷ giá
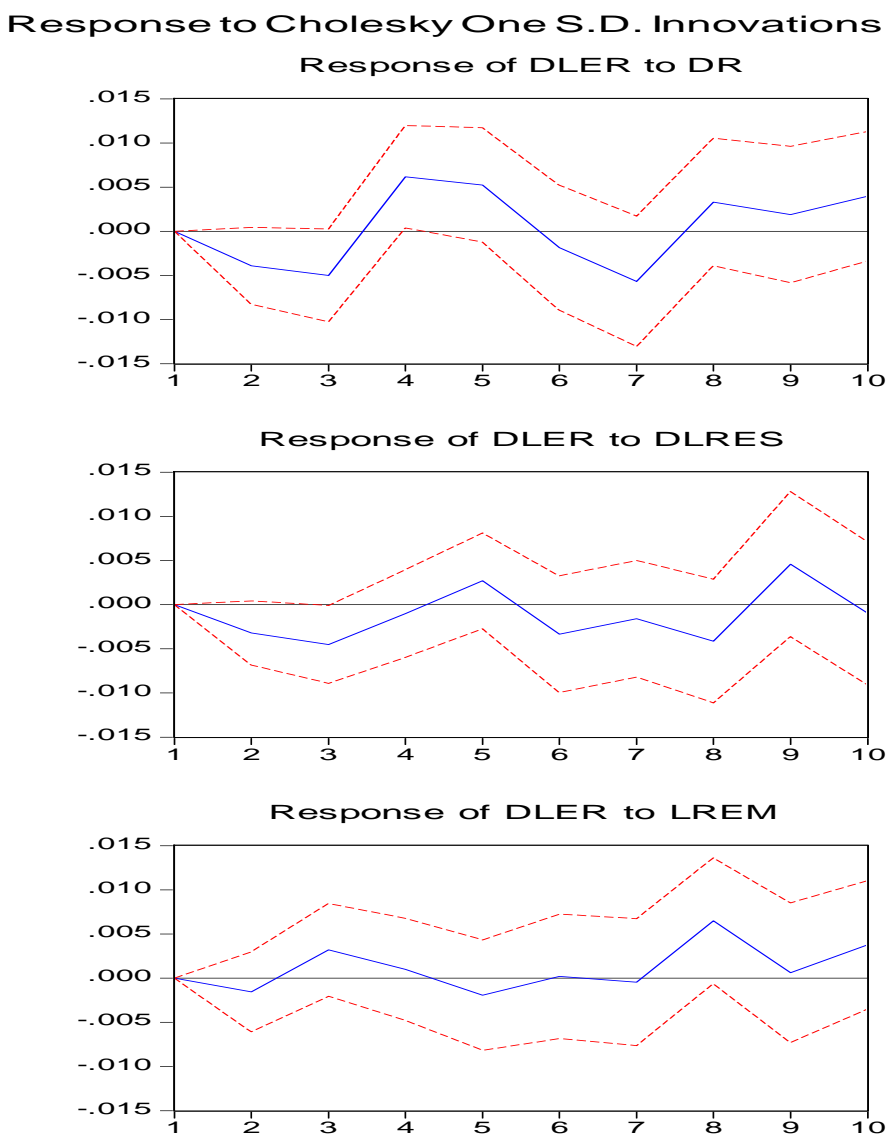

Nguồn: Phân tích tì̀ Eviews 6

\section{Kết luận}

Bằng việc ước lượng mô hình $\mathrm{VAR}$ với độ trễ $\mathrm{p}=5$ kết hợp với việc kiểm định nhân quả Granger và phân tích hàm phản ứng xung bài nghiên cứu đã phần nào đạt được mục tiêu nghiên cứu đề ra ban đầu.

Kết quả nghiên cứu thực nghiệm cho thấy tại Việt Nam, các yếu tố kinh tế vĩ mô thuộc về chính sách tiền tệ của NHNN bao gồm lãi suất, dự trữ ngoại hối mới là các yếu tố chính tác động đến tỷ giá USD. Ngoài các yếu tố đó, chỉ có yếu tố kiều hối Việt 
Nam cũng góp phần tác động tới tỷ giá. Kết quả này khá phù hợp với tình hình kinh tế cũng như cơ chế kiểm soát tỷ giá tại Việt Nam. Dù định hướng chính sách là để thả nổi có sự can thiệp của $\mathrm{NHNN}$, tuy nhiên $\mathrm{NHNN}$ thường can thiệp rất sâu vào thị trường ngoại hối bằng việc hạn chế giao dịch USD tự do trong nền kinh tế hay quy định một khung tỷ giá cho hệ thống ngân hàng thương mại. Xét về bản chất Việt Nam vẫn theo đuổi chế độ neo tỷ giá, trong đó tỷ giá chính thức sẽ công bố căn cứ vào các cú sốc trong nền kinh tế còn tỷ giá giao dịch của ngân hàng thương mại sẽ được dao động xoay quanh tỷ giá này ${ }^{8}$. Với các chính sách như trên, thì tỷ giá Việt Nam gắn liền với chính sách tiền tệ từng thời kỳ mà ít bị tác động bởi các yếu tố liên quan đến cung cầu cũng là điều dễ hiểu.

Cụ thể, kết quả phân tích IRF cho thấy yếu tố lãi suất tác động mạnh mẽ đến tỷ giá tại Việt Nam trong khoảng ba quý tiếp theo. Việc tăng lãi suất sẽ khiến dòng đầu tư vào Việt Nam tăng lên (cung ngoại tệ tăng), luồng đầu tư từ Việt Nam ra nước ngoài giảm đi (cầu ngoại tệ giảm), dẫn đến tỷ giá USD tại Việt Nam giảm. Ngược lại, việc giảm lãi suất sẽ khiến tỷ giá tăng lên. Yếu tố kiều hối cũng có tác động nghịch chiều tới tỷ giá trong các kỳ đầu tiên như lý thuyết kinh tế dự báo, tuy nhiên tác động này là chưa rõ rệt và chưa có ý nghĩa thống kê.

Mặt khác, kết quả nghiên cứu lại cho thấy một số vấn đề trái với dự báo của lý thuyết kinh tế vĩ mô như sau. Thứ nhất, yếu tố lãi suất thực của nền kinh tế Hoa Kỳ không có tác động đến tỷ giá USD tại Việt Nam. Điều này có thể giải thích do USD tại Việt Nam không chỉ được sử dụng trong các giao dịch xuất nhập khẩu hay đầu tư quốc tế với Hoa Kỳ mà nó với hầu hết các quốc gia khác. Do đó, tỷ giá đồng USD chưa chịu tác động từ các nhân tố thuộc về kinh tế vĩ mô của Hoa Kỳ cũng hoàn toàn phù hợp.

Ngoài ra, yếu tố dự trữ ngoại hối có tác động đến tỷ giá trong ba kỳ đầu tiên nhưng lại là tác động ngược chiều, ngược lại với những gì mà lý thuyết kinh tế dự báo. Điều này có thể do tỷ giá trên thị trường Việt Nam diễn biến khá phức tạp và chịu ảnh hưởng nhiều từ các cú sốc trên thị trường thế giới chứ không chỉ các yếu tố kinh tế đã được đưa ra trong mô hình. Ví dụ như sau khi gia nhập WTO, dòng vốn đầu tư vào Việt Nam tăng đột biến dẫn đến nguồn cung ngoại tệ trong hai năm 2007 - 2008 tăng đột biến khiến tỷ giá USD giảm và VND lên giá mạnh. Tuy nhiên, đến giai đoạn tiếp theo, khủng hoảng kinh tế thế giới lại khiến xu hướng dòng vốn vào Việt Nam đổi chiều cộng với sức ép từ lạm phát, nhập siêu, chênh lệch lớn giữa giá vàng trong nước và quốc tế, tâm lý lo ngại về việc VND mất giá. Tất cả những yếu tố trên khiến tỷ giá diễn biến vô cùng phức tạp, chênh lệch giữa tỷ giá chính thức và tỷ giá thực tế lên cao

\footnotetext{
${ }^{8}$ Theo Báo cáo kinh tế vĩ mô 2014, nhóm tư vấn chính sách kinh tế.
} 
đến mức cận trần buộc NHNN phải điều chính mức dao động một cách liên tục ${ }^{9}$. Những ví dụ nói trên cho thấy, biến động tỷ giá là một yếu tố phức tạp, chịu ảnh hưởng của rất nhiều yếu tố kinh tế vĩ mô của một quốc gia kết hợp với những cú sốc khác chưa được tính hết trong mô hình nghiên cứu đưa ra.

\section{Hạn chế và đề xuất hướng nghiên cúu tiếp theo}

Trong phạm vi bài nghiên cứu này, chúng ta chưa giải đáp hết được câu hỏi về tác động của yếu tố vĩ mô tới tỷ giá vì chưa tính tới các yếu tố khác như các cú sốc xảy ra từ bên ngoài có thể tác động tới tỷ giá của Việt Nam. Ngoài ra, bài nghiên cứu cũng chưa đi sâu để phân tích được tại sao một số kết quả nghiên cứu thực nghiệm đưa ra lại trái với dự báo của lý thuyết kinh tế. Những hạn chế này mở ra một hướng đi mới cho các nghiên cứu tiếp theo bằng việc tiếp tục nghiên cứu các cú sốc lớn của nền kinh tế tới tỷ giá USD ở Việt Nam chứ không dừng lại ở các yếu tố kinh tế vĩ mô cơ bản.

\section{Tài liệu tham khảo}

\section{Tiếng Anh}

1. Andrew B. Abel, Ben S. Bernanke, Dean Croushore. 2007. "Macroeconomics".

2. Den Haan, Wouter J., Garey Ramey, and Joel Watson. 2000. "Job Destruction and Propagation of Shocks." American Economic Review, 90(3)

3. Dornbusch, Rudiger (1976), "Expectations and exchange rate dynamics", Journal of Political Economy 84, 1161-1176.

4. Fredric S. Mishkin, Kent Matthews, Massimo Giuliodori (2012) "The Economics of Money, Banking and Financial Market".

5. IMF (2009) “International Transactions in Remittance, Guide for Compliers and Users", p. 18,19.

6. Frait, Jan and Komárek, Luboš (2001) Real exchange rate trends in transitional countries. Working Paper. Coventry: University of Warwick, Department of Economics. Warwick economic research papers (No.596).

7. Frenkel, Jacob A. and Michael L. Mussa. "Asset Markets, Exchange Rates andthe Balance of Payments." Handbook of International Economics, Vol. II, edited by R.W. Jones and P.B. Kenen, pp. 679-747. Amsterdam: Elsevier Science Publishers B.V., (1985).

\footnotetext{
${ }^{9}$ Theo báo cáo kinh tế vĩ mô 2014.
} 
8. Mills, T. and G. Wood (1978), "Money-Income Relationships and the Exchange Rate Regime, Review," Federal Reserve Bank of St. Louis 60, 22-27.

9. Kouri, Pentti (1976a), "The Exchange rate and the balance of payments in the short run and in the long run: a monetary approach", The Scandinavian Journal of Economics, 78 no. 2, pp. 280-304.

10. Gregory Mankiw. 2012. "Macroeconomics", Worth Publishers.

11. Đỗ Thị Kim Hảo. 2011."Đánh giá một số tác động của kiều hối tới nền kinh tế Việt Nam.” Tạp chí Khoa học và Đào tạo ngân hàng, số 107.

12. Lê Thị Tuấn Nghĩa, Phạm Thị Hoàng Anh. 2013. "Quy mô và cơ cấu dự trữ ngoại hối Việt Nam thời kỳ hậu WTO.”Tạp chí Ngân hàng, số 2-3, tr23-27.

13. Nguyễn Đức Thành. 2008. "Từ cuộc tranh luận kinh tế học vĩ mô về kiều hối đến những bài học cho Việt Nam hiện nay.” Tạp chí Những vấn đề Kinh tế và Chính trị thế giới, số tháng 4.

14. Nhóm tư vấn chính sách Kinh tế vĩ mô, Uỷ ban Kinh tế của Quốc hội, "Báo cáo kinh tế vĩ mô 2014”, Nxb Tri thức.

15. Phạm Minh Chính, Vương Quân Hoàng. 2010. Kinh tế Việt Nam: Thăng trầm và đột phá. Nxb Chính trị Quốc gia, Hà Nội. 